\title{
Expression and Chromosomal Assignment of a Novel Protein- Tyrosine Kinase Gene Related to the Insulin Receptor Family
}

\author{
A. R. Bauskin ${ }^{1}$, M. Zion ${ }^{1}$, J. Szpirer ${ }^{2}$, C. Szpirer ${ }^{2}$, M. Q. Islam ${ }^{3}$, G. Levan ${ }^{3}$, \\ G. Klein ${ }^{4}$, and Y. Ben-Neriah ${ }^{1}$
}

\section{A. Introduction}

There is growing evidence in recent literature for the involvement of protein-tyrosine phosphorylation in the early events of leukocyte activation. Interleukin-3 (IL-3), a growth factor essential for the growth of hematopoietic stem cells, myeloid cells, and possibly early lymphoid cells induces rapid phosphorylation of several cellular proteins in different IL-3-dependent cells (B. Isfort and J. Ihle, personal communication; [1]). One of the early events in T-cell activation is the tyrosine phosphorylation of a component of the T-cell antigen receptor [2]. Macrophage proliferation in response to M-CSF is mediated through the activation of the tyrosine kinase moiety of its receptor, the $c$-fms proto-oncogene [3].

The protein-tyrosine kinases described to date are either transmembrane proteins having an extracellular ligand binding domain [3-8] or cytoplasmic proteins related to the $v$-src oncogene [911]. Most of these proteins are expressed in a wide variety of cells and tissues; few are tissue specific [12]. Previous studies have suggested that lymphokines may mediate hematopoietic cell survival via

\footnotetext{
1 The Lautenberg Center for General and Tumor Immunology, The Hebrew University Hadassah Medical School, Jerusalem, Israel

${ }^{2}$ Departement de Biologie Moléculaire, Université Libre de Bruxelles, Belgium

3 Department of Genetics, University of Gothenburg, Göteborg, Sweden

${ }^{4}$ Department of Tumor Biology, Karolinska Institute, Stockholm, Sweden
}

their action on glucose transport $[13,14]$ which is regulated in some cells through the protein-tyrosine kinase activity of the insulin receptor [15]. As activation of glucose transport may be essential to hematopoietic cell growth, we investigated the possibility that insulin receptor-like genes are expressed specifically in hematopoietic cells. Using the insulin-receptor related avian sarcoma oncogene, $v$-ros as a probe [16], we isolated and characterized the complementary DNA of a novel gene denoted ltk (leukocyte tyrosine kinase), which is expressed mainly in leukocytes and has so far unique structural properties; ltk appears to encode a transmembrane protein devoid of an extracellular domain and is related to several tyrosine kinase receptor genes of the insulin receptor family [17].

\section{B. Results and Discussion}

The polypeptide predicted from the ltk cDNA sequence has a molecular mass of 52212 Daltons, and when plotted according to the hydrophilicity table of Hopp and Woods [18], reveals a predominant stretch of 26 hydrophobic amino acids at the $\mathrm{N}$-terminus of the polypeptide (positions 9-34), followed by three polar amino acids (Fig. 1). This region, albeit having an unusual position, is compatible with the properties of a transmembrane domain and the positively charged peptide (Asn-Gln-Lys) may serve as a membrane transfer stop signal. Following the hydrophobic stretch is a region homologous to the cytoplasmic region of protein kinases having the characteristics of a protein-tyrosine kinase domain [12]. 


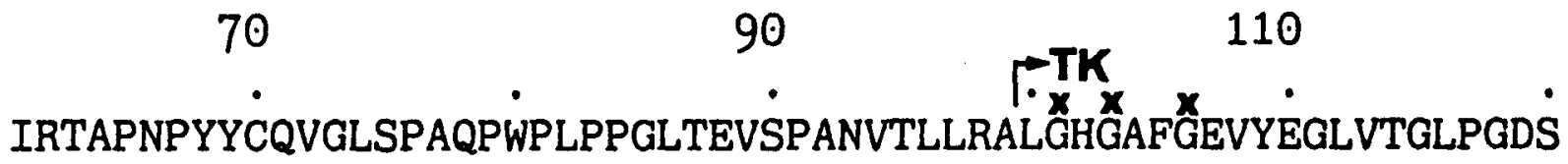

$130 \quad 150 \quad 170$

SPLPVAIKTTLPELCSHQDELDFLMEALIISKFSHQNIVRCVGLSFRSAPRLILLELMSGG

$190210 \quad 230$

DMKSFLRHSRPHPGQLAPL'TMQDLLQLAQDIAQGCHYLEENHFIHRDIAARNCLLSCSGA

$250 \quad 270 \quad 290$

SRVAKIGDFGMARDIYQASY̌YRKGGRTLLPVKWMPPEALLEGLFTSKTDSWSFGVLLWEI

$310 \quad 330 \quad 350$

FSLGYMPYPGHTNQEVLDFIATGNRMDPPRNCPGPVYRIMTQCWQHQPELRPDFGSILER

$370 \quad 390 \quad 410$

IQYCTQDPDVLNSPLPVEPGPILEEEEASRLGNRSLEGLRSPKPLELSSQNLKSWGGGLட்

$430 \quad 450$

\section{GSWLPSGLKTLKPRCLQPQNIWNPTYGSWTPRGPQGEDTGIEHCNGSSSSSIPGIQ}

Fig. 1. Predicted protein sequence of $l t k$. The putative transmembrane region is underlined with a solid bar. Asterisks: Gly 101, Gly 103, Gly 106, and Lys 128 indicate the potential ATP binding site; and Tyr 260 , the putative autophosphorylation site. The tyrosine kinase (TK) domain is indicated by arrows

A search through the GenBank protein data-bank reveals that $l t k$ shares a high degree of similarity throughout the tyrosine kinase domain with receptor proteins. These include the human c-ros protein protein $(53 \%)$ [19], the Drosophila hemeotic protein sev $(49 \%)$ [20], the human receptors for insulin and insulin-like growth factor-1 (IGF-1) $(48 \%)[5,8]$ and the receptor portion of 
the human trk protein (45\%) [21]. Comparison of $l t k$ with other kinase-receptor proteins reveals a lower degree of similarity: $30 \%-38 \%$. With the former group of receptor proteins $l t k$ shares a unique peptide: Tyr-Tyr-Arg-Lys-X-Gly-X-XLeu-Leu-Pro-Val at the autophosphorylation site. Interestingly, the insulin and IGF-1 receptors are among the few kinases where autophosporylation activates the kinase activity of the protein [22-24]. It therefore seems that ltk, together with the former group of kinasereceptor genes, forms a subfamily within the protein-tyrosine kinase family. It remains to be seen whether the members of this subfamily are also functionally related.

In the mouse and human genome ltk is transcribed from a single copy gene. Using a series of mouse-human and rat-human cell hybrids we assigned the human ltk gene to chromosome 15 (Fig. 2, Table 1). Interestingly, the closely related IGF1 receptor gene is also located on human chromosome 15.

The expression of $l t k$ was analyzed in different murine tissues. Northern blot analysis revealed two transcripts in RadLV transformed T-cell lines, Tc38 and Tc23 [25] (Fig. 3a) and in the thymus (not shown) of approximately $2.6 \mathrm{~kb}$ and $3.0 \mathrm{~kb}$. The expression of $l t k$ in the various mouse tissues and cell lines was quantified by RNA slot-blot hybridization analysis using a $5^{\prime}$ ltk probe (exclud- ing the kinase coding region; Fig. $3 \mathrm{~b}$ ), ltk was abundant in the thymus and observed in the spleen and kidney. Among the different cell lines, $l t k$ was expressed in an interleukin-2 (IL-2) dependent ltk line, CTLD4; a macrophage colony stimulating factor (M-CSF) dependent macrophage cell line, Mac26; in the IL-3 dependent cell line, $\mathrm{Ba} / \mathrm{F} 3$, which is thought to be an early pre-B-lymphocyte line (R. Palacios, personal communication); and in mouse lymphokine activated killer (LAK) cells. Rehybridization of the blot with a ltk kinase region probe shows a similar tissue distribution except for an additional faint signal in the brain (not shown). It thus appears that $l t k$ is expressed mainly in cells of hematopoietic origin.

Considering the homology of ltk to transmembrane protein kinases, it was expected to include an extracellular recognition unit. However, the putative external portion of the protein is only nine amino acids long and unlikely to be sufficient for ligand binding. It is possible that one of the two transcripts detected by the $l t k$ probe (Fig. $3 \mathrm{a}$ ) encodes another protein with a larger extracytoplasmic domain. $\mathrm{N}$-terminal variation has been observed in several other proteintyrosine kinases as a result of alternative mRNA splicing $[11,26]$. The $c-a b l$ protooncogene generates two mRNA transcripts of 5.5 and $6.5 \mathrm{~kb}$ by alternative splicing, each encoding a protein with a

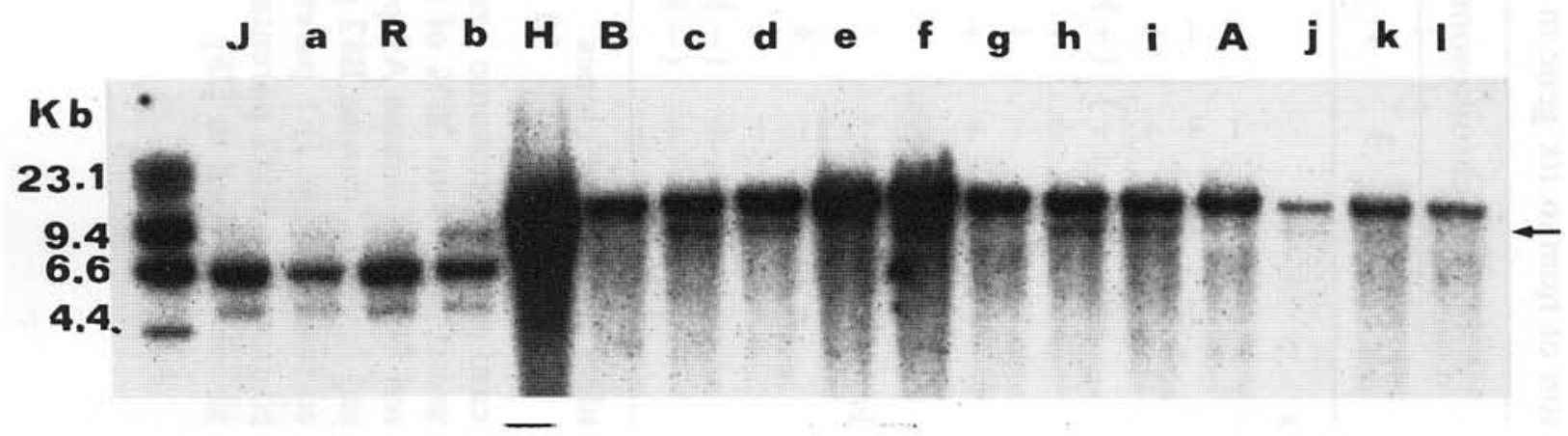

Fig. 2. Mapping of the $l t k$ gene to human chromosome 15 . Sourthern blot analysis of DNA $(10 \mu \mathrm{g})$ from mouse cell lines, $\mathrm{A} 9(A)$ and $\mathrm{B} 82(B)$; rat cell lines, JF1 $(J)$ and Rat $2(R)$; human HeLa cell line $(H)$; mouse-human and rat-human hybrids, whose chromosomal content is indicated in Table 1 . The DNA was digested with an excess of the restriction enzyme HindIII, fractionated in $1 \%$ agarose, transferred to a nylon membrane filter (Zetabind), and hybridized to a ${ }^{32} \mathrm{P}$ radiolabeled $l t k$ cDNA probe. The position of human ltk is indicated by an arrow 
Table 1. Detection of human ltk gene in human $\times$ rat and human $\times$ mouse hybrids

\begin{tabular}{|c|c|c|c|c|c|c|c|c|c|c|c|c|c|c|c|c|c|c|c|c|c|c|c|c|}
\hline \multirow[t]{2}{*}{ Hybrids } & \multicolumn{24}{|c|}{ Human chromosomes } \\
\hline & 1 & 2 & 3 & 4 & 5 & 6 & 7 & 8 & 9 & 10 & 11 & 12 & 13 & 14 & 15 & 16 & 17 & 18 & 19 & 20 & 21 & 22 & $X$ & $\mathrm{Y}$ \\
\hline \multicolumn{25}{|c|}{ Positive hybrids } \\
\hline $\mathrm{j}-\mathrm{HA} 221^{\mathrm{a}}$ & - & - & - & + & - & + & + & - & - & - & + & - & - & - & + & - & + & - & + & - & + & - & + & - \\
\hline $\mathrm{i}-\mathrm{HB} 26^{\mathrm{b}}$ & - & - & + & - & - & + & + & - & - & + & $(+)$ & $(-)$ & + & + & + & + & + & + & $(+)$ & + & + & + & - & - \\
\hline h-HB29 ${ }^{b}$ & - & - & + & + & - & + & + & + & + & + & + & + & + & + & + & + & + & + & + & + & + & + & - & - \\
\hline g-HB33 ${ }^{b}$ & - & - & $(+)$ & $(+)$ & - & + & - & + & - & - & $(+)$ & - & - & + & - & - & $(+)$ & $(-)$ & - & - & - & + & - & - \\
\hline$f-H B 43^{b}$ & + & + & + & + & - & + & + & + & - & - & + & + & - & + & + & + & + & + & + & + & + & + & + & - \\
\hline d-HB142.2 ${ }^{b}$ & - & - & - & + & - & - & - & - & - & - & - & - & - & + & + & - & + & - & - & - & - & - & - & - \\
\hline c-HB182b & - & - & + & + & + & + & + & + & - & - & + & + & + & + & + & - & + & + & + & + & + & + & - & - \\
\hline b-HR $40 C 8^{d}$ & - & - & - & - & - & - & + & - & - & + & - & + & + & + & + & $(-)$ & + & - & + & + & + & $(+)$ & + & - \\
\hline \multicolumn{25}{|c|}{ Negative hybrids } \\
\hline 1-HA11 a & - & - & - & + & + & + & - & + & - & - & + & - & - & - & - & - & + & - & - & + & + & - & - & - \\
\hline $\mathrm{k}-\mathrm{HA} 13^{\mathrm{a}}$ & + & - & - & + & + & + & - & + & - & - & + & + & - & - & - & + & + & - & + & + & + & - & + & - \\
\hline e-HB1 12b & - & - & + & $(-)$ & - & - & - & $(-)$ & - & - & + & + & - & + & - & - & + & - & - & - & + & - & - & - \\
\hline a-JV211 & + & $(-)$ & + & $(-)$ & + & + & + & + & - & + & + & + & - & - & - & + & - & - & - & + & - & + & - & \\
\hline
\end{tabular}

Percent independent discordant clones

$$
\begin{array}{llllllllllllllllllllllll}
80 & 60 & 40 & 30 & 70 & 40 & 30 & 60 & 70 & 60 & 20 & 60 & 40 & 20 & 10 & 60 & 20 & 30 & 30 & 60 & 40 & 30 & 50 & 70
\end{array}
$$

The symbols mean: + , chromosome present in at least $60 \%$ of the metaphases; $(+)$, chromosome present in $30 \%$ to $50 \%$ of the metaphases; $(-)$, chromosome present in $10 \%$ to $20 \%$ of the metaphases; -, chromosome absent.

a Hybrids derived from the mouse A9 parental cell.

b Hybrids derived from the mouse B82 parental cell.

c Hybrid derived from the rat JF1 parental cell.

d Hybrid derived from the Rat 2 parental cell.

The hybrids used are described in [28]. 


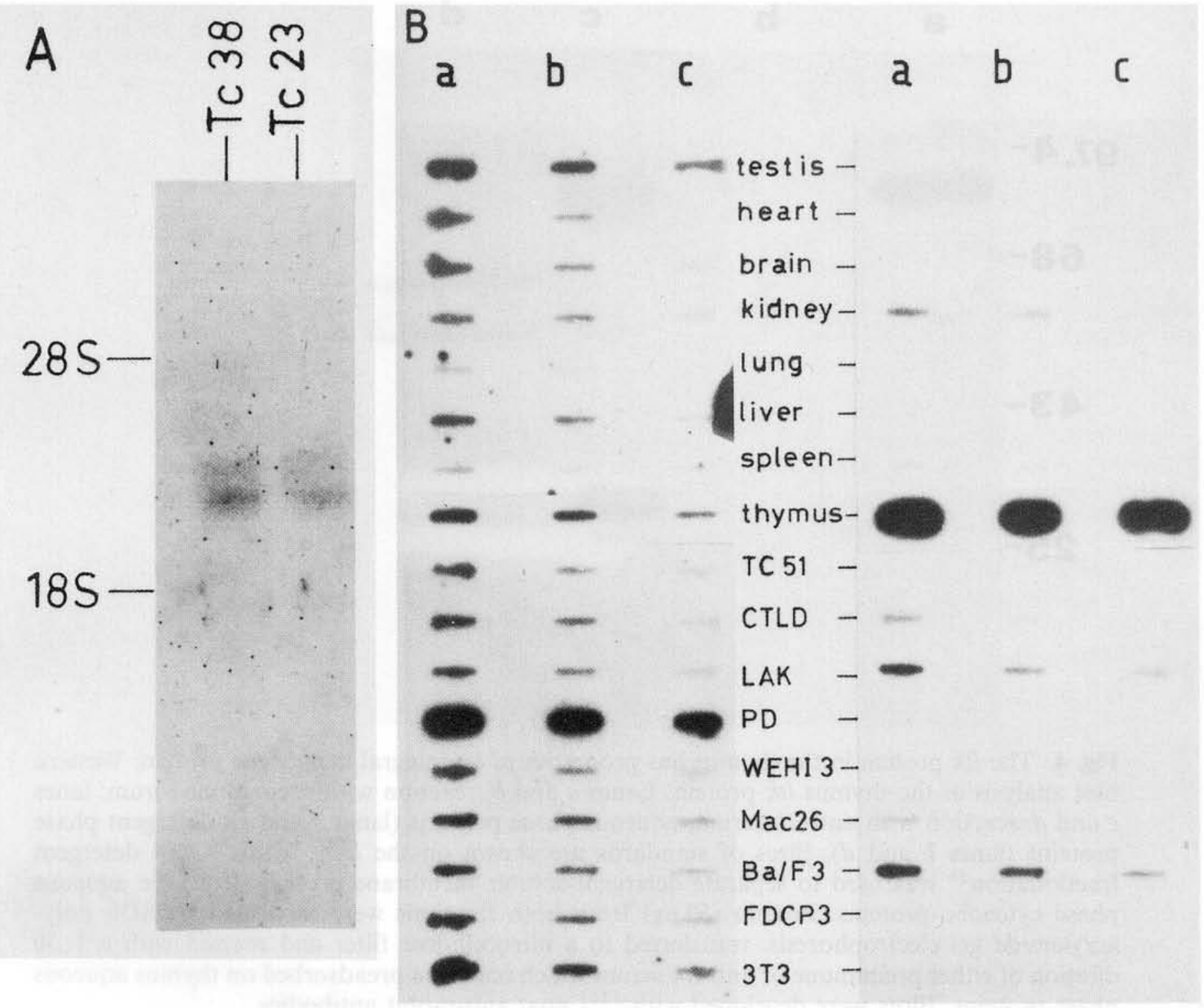

Fig. 3A, B. Expression of $l t k$ in different murine tissues and cell lines. A Northern blot analysis of poly(A) ${ }^{+}$RNA from Rad-LV transformed T-cell lines [22]. Poly(A) ${ }^{+}$RNA was extracted by $\mathrm{LiCl}_{2}$-urea lysis and phenol/chloroform extraction, followed by Oligo(dT) selection and separated on a formaldehyde-containing $1 \%$ agarose gel $(5 \mu \mathrm{g} / \mathrm{lane})$. The RNA was transferred to Zetabind nylon membrane and hybridized to radiolabeled $l t k \mathrm{cDNA}$ probe. B Slot-blot analysis of total cellular RNA isolated from different murine tissues and cell lines. RNA, $30 \mu \mathrm{g}(a), 10 \mu \mathrm{g}$ $(b)$, and $3 \mu \mathrm{g}(c)$ was spotted onto nitrocellulose using the Minifold II slot-blotter (Schleicher and Shuell) and hybridized with a radiolabelled $c$-abl kinase region probe as a control, left panel; and a radiolabelled $5^{\prime}$ ltk fragment, right panel. Cell lines: TC51, Rad-LV transformed T-cell line [22]; CTLD, an IL-2 dependent T-cell line; LAK, lymphokine activated killer cells were prepared by incubating splenocytes with IL-2 $(1000 \mathrm{U} / \mathrm{ml})$ for 5 days; PD, Abelson-MuLV transformed pre-B cell line; WEHI 3, macrophage/monocyte line; Mac 26, a M-CSF dependent bone marrow derived macrophage line; Ba/F3, and IL-3 dependent lymphoid line; FDCP 3, a GM-CSF dependent myeloid line; $3 \mathrm{~T} 3$, a fibroblast line from $\mathrm{C} 3 \mathrm{H}$ mouse

different $\mathrm{N}$-terminus [11]. If the origin of the two ltk transcripts is similar, we may have characterized one alternative splice form, while the other may encode a different N-terminus. Nevertheless, S1 nuclease analysis showed transcripts fully complementary to the $l t k$ cDNA clone in the thymus.

To demonstrate that $l t k$ encodes a transmembrane protein, $l t k$-specific antiserum was prepared against an $l t k / \beta$ galactosidase fusion protein and used to 


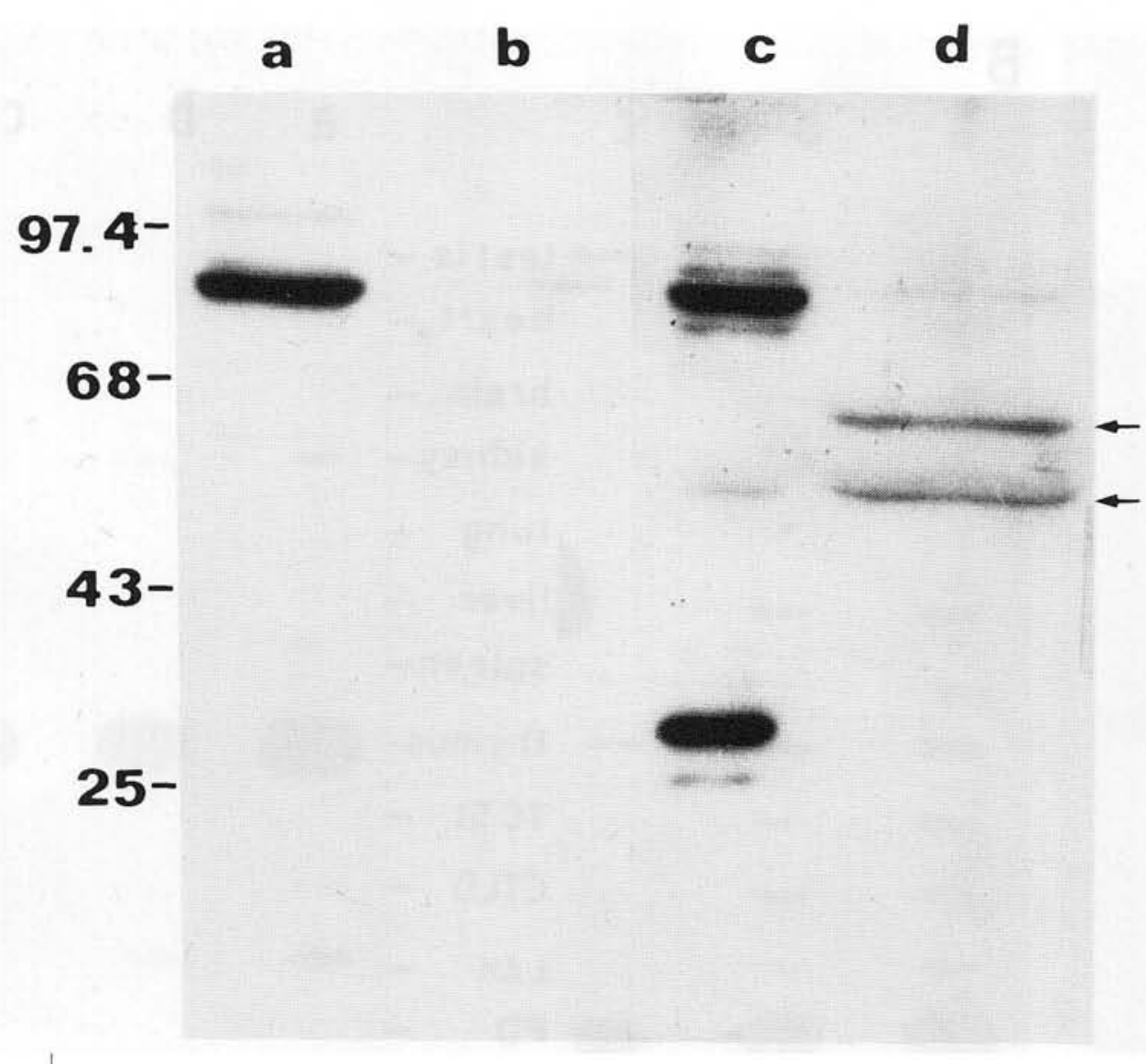

Fig. 4. The $l t k$ protein in the thymus has properties of an integral membrane protein. Western blot analysis of the thymus $l t k$ protein. Lanes $a$ and $b$, reaction with preimmune serum; lanes $c$ and $d$, reaction with anti-ltk serum; aqueous phase proteins (lanes $a$ and $c$ ); detergent phase proteins (lanes $b$ and $d$ ). Sizes of standards are shown on the left. Triton X-114 detergent fractionation $^{28}$ was used to separate detergent-soluble membrane proteins from the aqueous phase cytosolic proteins. Protein $(50 \mu \mathrm{g})$ from both fractions were separated by SDS polyacrylamide gel electrophoresis. transferred to a nitrocellulose filter and reacted with a 1:50 dilution of either preimmune or anti-ltk serum which had been preadsorbed on thymus aqueous phase proteins. Blots were developed with ${ }^{125}$ I goat anti-rabbit antibodies

demonstrate the presence of $l t k$ protein in a thymus membrane protein fraction (Fig. 4). The specificity of the serum was shown by immunoprecipitation of ltk protein. The largest protein band synthesized in rabbit reticulocyte lysate has a molecular mass of $52 \mathrm{kD}$ in agreement with the predicted size of the protein encoded by the long open reading frame of $l t k$ and is immunoprecipitated by $l t k$ specific antisera (not shown).

Western blot analysis of membrane fractionated thymus proteins showed that anti-ltk serum reacts specifically with two protein bands of 56 and $64 \mathrm{kD}$ in the thymus membrane fraction (Fig. 4). The $56 \mathrm{kD}$ band is consistent with the expected size of the encoded protein, while the $64 \mathrm{kD}$ band may repre- sent either a second $l t k$ gene product due to alternative splicing alternative translation-initiation or a cross-reactive protein.

These results show that authentic ltk transcripts exist in thymocytes encoding a protein with features of a transmembrane catalytic subunit. The unusual structure of the putative ltk protein implies a role in signal transduction. Thymocytes, B cells, and the various other cells which express the gene, grow and differentiate in response to various extracellular stimuli. Protein-tyrosine phosphorylation appears to be involved in the signal transduction of such stimuli. However, with the exception of the M-CSF receptor, a specific tyrosine-kinase has yet to be identified in the other signal transduction pathways. Therefore, ltk is 
a candidate transducer for early activation events in leukocytes.

Acknowledgement. This work was supported by awards from the Israel Academy of Science - Basic Research Fund and the Israel Cancer Research Fund, the Fund for Medical Scientific Research (Belgium), and the Swedish Cancer Society and Erik Sörensen Foundation. Part of the work was undertaken during the tenure of the International Union Against Cancer (ICRETT) personal exchange award (to Y.B.-N.).

\section{References}

1. Morla AD et al. (1988) Haematopoietic growth factors activate the tyrosine phosphorylation of distinct sets of proteins in Interleukin-3-dependent murine cell lines. Mol Cell Biol 8:2214-2218

2. Baniash $\mathrm{M}$ et al. (1988) The T-cell antigen receptor zeta chain is tyrosine phosphorylated upon activation. J Biol Chem 263:18225-18230

3. Sherr CJ et al. (1985) The c-fms protooncogene product is related to the receptor for the mononuclear phagocyte growth factor CSF-1. Cell 41:665-676

4. Ebina $Y$ et al. (1985) The human insulin receptor cDNA: the structural basis for hormone activated transmembrane signalling. Cell 40:747-758

5. Ulrich A et al. (1985) Human insulin receptor and its relationship to the tyrosine kinase family of oncogenes. Nalture 313:756-761

6. Ulrich A et al. (1984) Human epidermal growth factor receptor cDNA sequence and aberrant expression of the amplified gene in A431 epidermoid carcinoma cells.

7. Yarden $Y$ et al. (1986) Structure of the receptor for platelet-derived growth factor helps define a family of closely related growth factor receptors. Nature 323:226 232

8. Ulrich A et al. (1986) Insulin-like growth factor 1 receptor primary structure: comparison with insulin receptor suggests structural determinants that define functional specificity. EMBO J 5:2508-2512

9. Snyder MA, Bishop JM, Colby WW, Levinson AD (1983) Phosphorylation of tyrosine- 416 is not required for the transforming properties of $\mathrm{pp} 60^{\mathrm{scr}}$. Cell 32:891-901
10. Cross FR, Hanafuza H (1983) Local mutagenesis of Rous sarcoma virus: The major sites of tyrosine and serine phosphorylation are dispensable for transformation. Cell 34:597-607

11. Ben-Neriah $Y$, Bernards A, Paskind $M$, Daley GQ, Baltimore D (1986) Alternative $5^{\prime}$ exons in $c$ - $a b l$ mRNA. Cell 44:577586

12. Hunter $\mathrm{T}$ (1987) A thousand and one protein kinases. Cell 50:823-829

13. Whetton AD, Bazill GW, Dexter TM TM (1984) Haematopoietic cell growth factor mediates cell survival via its action on glucose transport. EMBO J 3:409-413

14. Dexter MT et al. (1986) The relevance of protein kinase $\mathrm{C}$ activation, glucose transport and ATP generation in the response of haematopoietic cells to growth factors. In: Kahn P, Graf T (eds) Oncogenes and growth control. Springer, Berlin Heidelberg New York, pp 163-169

15. Goldfine ID (1987) The insulin receptor: Molecular biology and transmembrane signalling. Endocr Rev 8:235-255

16. Neckameyer WS, Wang LH (1985) Nucleotide sequence of avian sarcoma virus UR2 and comparison of its transforming gene with other members of the tyrosine protein kinase. J Virol 53:879-884

17. Ben-Neriah Y, Bauskin AR (1988) Leukocytes express a novel gene encoding a putative transmembrane protein-kinase devoid of an extracellular domain. 333:672-676

18. Hopp TP, Woods KR (1981) Prediction of protein antigenic determinants from amino acid sequences. Proc Natl Acad Sci USA 78:3821-3824

19. Matsushime $H$, Wang LH, Shibuya M (1986) Human c-ros-1 gene homologous to the v-ros sequence of UR2 sarcoma virus encodes for a transmembrane receptor-like molecule. Mol Cell Biol 6:30003004

20. Hafen E, Basler K, Edstroem J, Rubin GM (1987) Sevenless, a cell-specific homeotic gene of Drosophila, encodes a putative transmembrane receptor with a tyrosine kinase domain. Science 236:5563

21. Martin-Zanca D, Hughes SH, Barbacid M (1986) A human oncogene formed by the fusion of truncated tropomyosin and protein tyrosine kinase sequences. Nature 319:743-748

22. Yu KT, Peters MA, Czech MD (1986) Similar control mechanisms regulate the 
insulin and type 1 insulin-like growth factor receptor kinases. J Biol Chem 261:11341-11349

23. Rosen OM, Herrara R, Olowe Y, Pelruzelli LM, Cobb MH (1983) Phosphorylation activates the insulin receptor tyrosine kinase. Proc Natl Acad Sci USA 80:3237-3240

24. Sibley DR, Benovic JL, Caron MG, Lefkowitz RJ (1987) Regulation of transmembrane signaling by receptor phosphorylation. Cell 48:913-922

25. Azar $Y$ et al. (1981) Antigen-specific mu- rine T-cell lymphomas: Functional heterogenicity. Cell Immunol 65:194-200

26. Schejter ED et al. (1986) Alternative 5' exons and tissue specific expression of the Drosophila EGF receptor homolog transcripts. Cell 46:1091-1101

27. Bordier C (1981) Phase separation of integral membrane proteins in Triton-X-114 solution. J Biol Chem 256:1604-1607

28. Wathelet MG et al. (1988) Cloning and chromosomal location of human genes inducible by Type 1 Interferon. Somatic Cell Mol Genet 14:415-426 